\title{
Calling Out to Isis
}

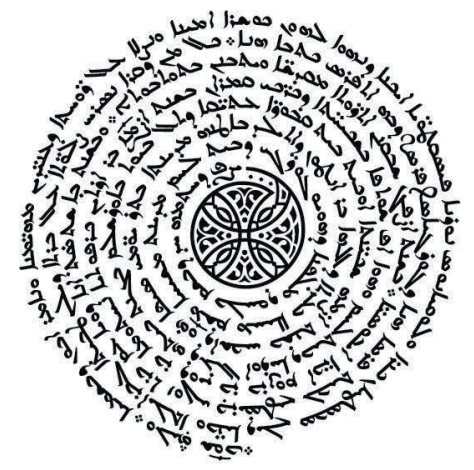




\title{
Gorgias Studies in the Ancient Near East
}

13

\author{
Series Editorial Board \\ Ronald Wallenfels (Chair) \\ Paul Collins \\ Aidan Dodson \\ Alhena Gadotti \\ Kay Kohlmeyer \\ Adam Miglio \\ Beate Pongratz-Leisten
}

This series publishes scholarly research focusing on the societies, material cultures, technologies, religions, and languages that emerged from Mesopotamia, Egypt, and the Levant. Gorgias Studies in the Ancient Near East features studies with both humanistic and social scientific approaches. 


\section{Calling Out to Isis}

The Enduring Nubian Presence at Philae

Solange Ashby

\footnotetext{
Gorgias

2020
} 
Gorgias Press LLC, 954 River Road, Piscataway, NJ, 08854, USA

www.gorgiaspress.com

Copyright (C) 2020 by Gorgias Press LLC

All rights reserved under International and Pan-American Copyright Conventions. No part of this publication may be reproduced, stored in a retrieval system or transmitted in any form or by any means, electronic, mechanical, photocopying, recording, scanning or otherwise without the prior written permission of Gorgias Press LLC.

2020

$x$

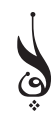

ISBN 978-1-4632-0715-1

\section{Library of Congress Cataloging-in-Publication Data}

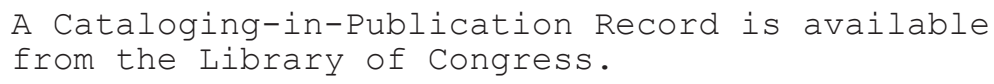

Printed in the United States of America 
This book is dedicated to the memory of Eugene David Cruz-Uribe (December 22, 1952 - March 12, 2018) an excellent scholar, fun guy, and my dissertation advisor.

His wisdom, guidance, and compassion have had a profound impact on this manuscript. 
